\title{
Satisfiers and Dissatisfiers: A Two-Factor Model for Website Design and Evaluation
}

\author{
Ping Zhang \\ School of Information Studies, Syracuse University, Syracuse, NY 13244. E-mail: pzhang@syr.edu \\ Gisela M. von Dran \\ School of Management, Syracuse University, Syracuse, NY 13244
}

\begin{abstract}
Proliferating Web-user interface studies prompt a need for theoretical approaches. This study presents a twofactor model that can guide Website design and evaluation. According to the model, there are two types of Website design factors: hygiene and motivator. Hygiene factors are those whose presence make a Website functional and serviceable, and whose absence causes user dissatisfaction (thus dissatisfiers). Motivator factors, on the other hand, are those that add value to the Website by contributing to user satisfaction (thus satisfiers). An empirical study is conducted in two phases. In Phase I, 44 core features and 12 categories of features were identified by a total of 76 subjects as Web design factors. In Phase II, 79 different subjects distinguished hygiene and motivator factors in the context of a particular Website (CNN.com). The results showed that the two-factor model provides a means for Web-user interface studies. In addition, Subjects in Phase II commented that, as time passes or familiarity increases with certain design factors, their identification of what are hygiene and motivator factors might change, promoting further investigation and possible expansion of the model. Suggestions for Website designs and evaluation, and further research directions are provided.
\end{abstract}

\section{Introduction}

With the swift development and increasing use of the World Wide Web as both an information-seeking and an electronic commerce tool, Web-user interface studies grow in significance. Poor interface functionality is one potential cause for web usability meltdown (Nielsen, 1999). Numerous Web design checklists have been developed with the intent to identify design and evaluation criteria for "great" or "terrible" Websites. Most of them are based on individual author's opinions and preferences, on criteria developed for other media, or for traditional user interface. Only a few

Received 7 December 1999; Revised 4 April 1999; accepted 6 June 2000

(C) 2000 John Wiley \& Sons, Inc. suggest a theoretical foundation (e.g., Conger \& Mason 1998; Small, 1998), or are supported by empirical evidence (e.g., Spool, Jared, Scanton, Schroeder, Snyder, \& DeAngelo, 1999; User Interface Engineering, 1996; Wilkinson, Bennett, \& Oliver, 1997). On examination of these existing checklists, three uncertainties emerge: (1) it is unclear whether there is an inclusive collection of design factors; (2) it is unclear whether some of these factors are more useful than other factors and in what aspect; and (3) it is unclear whether addressing these factors is sufficient to make users satisfied with the Websites, to keep their interest in the Websites, and eventually to motivate them to revisit the Websites. Thus the effectiveness of these checklists is largely unknown. In addition, most checklists pay scant attention to the affective and motivational aspects of the Web environment, aspects of increasing importance to differentiate those Websites that please users from those that turn people off. The real challenge is to identify and develop design factors that can (1) make a Website usable and serviceable, avoiding users frustration or dissatisfaction; (2) create more stimulating, visually pleasing, comprehensive, and commercially viable Websites; and (3) help attract users to a Website, maintain their interest in the Website, and encourage them to return to the Website again.

User satisfaction with a Website or users liking a Website is one of the many goals Web designers want to achieve. Satisfied users may spend a longer time at a Website, may revisit the Website, and may recommend the Website to others. These goals are particularly relevant with the increase of people depending more on the Web for acquiring information and conducting business. Therefore, it is useful to determine what makes a user satisfied with a Website as well as what may potentially dissatisfy. The findings of some existing empirical studies are often surprising and counterintuitive (Spool et al., 1999), pointing out the need for developing a theoretical framework and testing some assumptions that are taken for granted. 
The purpose of this study is to investigate Website design factors and their impact from a theoretical perspective. After examining the work place and the Web environment, we believe that the underlying goals for creating a motivating Website are similar to those for creating a motivating workplace: to provide the conditions and environment that minimize user (employee) dissatisfaction and maximize user (employee) satisfaction by allowing them to focus on and achieve high task performance. The researchers use an analogy to Herzberg's hygiene-motivator theory, and propose a two-factor model that can be used to distinguish those Website design factors that ensure essential functionality (thus hygiene factors) from those that increase users' satisfaction and motivate their return to a Website (thus motivator factors). In other words, designers, who want not only to minimize user dissatisfaction but also to encourage continued use, should be aware of both hygiene and motivator factors, and use the former as a necessary prerequisite for the latter. Empirical data are collected to show that Web users can use the hygiene and motivator concepts to identify the two types of design factors.

This article is organized as follows. The next section is the literature review on current Web evaluation studies, and motivational and job satisfaction theories in organizational behavior. The following section describes the empirical study methodology including Phase I for identifying design factors, and Phase II for identifying the hygiene and motivator characteristics of the factors. Finally, the researchers discuss the implications of the findings, some limitations, and directions for future research.

\section{Literature Review}

\section{Website Evaluation Studies}

Website evaluations or usability studies have been fruitful in the past several years. They include conceptual discussions on what should be evaluated and how to do it (e.g., Instone, 1997; Nielsen's Alertbox columns). Several people recommend applying the traditional usability criteria (e.g., Nielsen, 1993; Shneiderman, 1998) to the Web environment (e.g., Instone, 1997; Levi \& Conrad, 1996). There are other studies that develop criteria specifically for the Web. Most of the work in Web evaluation provides heuristics or checklists for Website evaluation with few or unknown theoretical bases and unclear empirical data support (e.g., Alexander \& Tate, 1999; Flanders \& Willis, 1998; Keeker, 1997). Among the few who used theoretical frameworks for Website evaluations, Small (1998) uses the ARCS model from instructional design as a base and has developed WebMAC (Web Motivational Assessment Checklist). Conger and Mason (1998) propose applications of theories to Website designs from other disciplines such as management, psychology, and political science. Smith (1997) reviews the evaluation criteria for print materials, and argues that the criteria in most cases could be applied to the Internet domain. He then developed a toolbox of criteria.
Among the handful of empirical studies, Wilkinson, Bennett, and Oliver (1997) first took a bottom-up approach by compiling Internet evaluation criteria from different sources. Then they asked $30 \mathrm{Web}$ evaluation experts to judge the importance of the criteria and whether a particular indicator rated for information quality or Website quality. The results of the survey showed that 71 information quality indicators and 67 Website quality indicators can be used to evaluate the quality of Internet information sources. With a similar focus on Internet information resource quality, Borges, Morales, and Rodriguez (1998) started from Nielsen's (1993) heuristics guidelines to evaluate 10 Websites for universities and colleges. Next, they did user testing of the guidelines by redesigning and retesting the university Websites, and then tested commercial Websites using the guidelines. Revised guidelines eventually were generated for designing usable Web pages. Spool et al. (1999) focused on information retrieval tasks and conducted usability studies on several large companies' Websites.

Despite these studies in Web-user interface design and evaluation, the testing or use of theoretical models is still rare. "Many empirical studies of interactive computer use have no theoretical orientation. Data is collected, but no underlying model or theory of the process exists to be confirmed or refuted. Such a model or theory would be very useful because with many design decisions there are too many alternative proposals to test by trial and error. A strong theory or performance model could reduce the set of plausible alternatives to a manageable number for testing" (Baecker, Grudin, Buxton, \& Greenberg, 1995, p. 573).

\section{User Information Seeking Tasks}

Existing user interface studies and other studies indicate that many potential factors may be involved when studying users interacting with user interfaces. The interaction between a user's task and the user interface characteristics is well known. The cognitive fit theory (Vessey, 1991) explains that performance will be enhanced when spatial information representations facilitate the spatial or perceptual type of tasks and symbolic information representations facilitate analytical type of tasks. According to Marchionini (1995), users' information-seeking tasks or searching behaviors make use of two classes of strategies-browsing and analytical strategies. Browsing is an informal and natural information seeking approach that depends heavily on the information environment and the user's recognition of relevant information. Analytical strategies, in contrast, depend on careful planning, recall of query terms, iterative query reformulation, and examination of results. The empirical evidence by Spool et al. (1999) led them to believe that because surfing is significantly different from information retrieval on the Web, designing for one may actually hurt a design for the other, and that it may not possible to design one site to meet both purposes.

The type or purpose of a Website usually implies the kind of tasks users can do with it, although this is not 
necessarily true. For example, people tend to go to CNN.com and Disney.com for different purposes, although both browsing and analytical tasks can be involved at both sites. Nevertheless, the types or purposes of a Website have a similar impact on user interaction with the Website as do task types. In this study, the researchers focus on a particular task in a particular Website to filter out potential sources of variance and gain insight into the credibility of the two-factor model for Website design and evaluation. Other types of tasks or Websites will be considered in future research.

\section{Motivational Theories and their Applications}

Motivation is one of the major individual level variables that determine productivity and job satisfaction. Job satisfaction, which is defined as an affective or emotional response to one's job (Kreitner \& Kinicki, 1998, p. 158) is associated with the factors identified by Herzberg as motivators, for example, achievement, recognition, characteristics of the work itself, responsibility, and advancement. Individuals attribute their positive feelings about these factors to themselves, and their intrinsic motivation.

The application of both content and process motivational theories developed for the workplace to an evolving technological context is not new. DeSanctis (1983), using expectancy theory to study whether motivation to use an information system was a function of expectancy, found that a user's positive attitudes toward information systems increase the actual use of the system. Similarly, Burton, Chen, Grover, and Stewart (1993), applying the same theory, concluded that users of a newly implemented system will continuously evaluate the outcomes of system use and subjectively assess the likelihood that their actions will lead to desired outcomes. Markus and Keil (1994) discussed how systems ought to be motivating because they, if well designed, make the users' jobs easier, and highlighted the role of individual factors that influence high or low motivation to use a system. Gill (1996) suggested that user satisfaction with a system could be enhanced through intrinsic motivational factors similar to those identified by Herzberg (1966, 1968, 1987). Among these are increased sense of user control, more task variety, less task routine, and provision for capabilities to move task performance to higher levels.

One of the challenges for many Websites is to identify design factors that help attract users to a Website, keep them there, and motivate them to return at a later time. The proliferating list of evaluation criteria for Websites provides little guidance to Web designers as to the relative value of design factors or why some factors are absolutely necessary for any Website (e.g., Alexander \& Tate, 1999; Borges et al., 1998; Flanders \& Willis, 1998; Instone, 1997; Keeker, 1997; Levi \& Conrad, 1996). Web designers may spend considerable time, attention, and other resources on design factors without a conscious understanding of the factors' impact. Comparable situations occur in management where managers need to understand what factors help worker satisfaction and motivation before they can create a satisfactory and motivating work environment.

For this study, the researchers adopted the dual structure of Herzberg's two-factor theory (1966, 1968, 1987). Herzberg's theory is based on the description of situations when professionals such as engineers and accountants felt exceptionally good or bad about their jobs. Herzberg found that certain characteristics tend to be consistently related to job satisfaction and others to job dissatisfaction. Factors having the potential to lead to job dissatisfaction were called hygiene factors by Herzberg because, if they were present, they tend to provide the basic conditions needed for satisfaction in normal work environments. They meet the basic physiological, safety, and social needs in the workplace (Maslow, 1954). Such factors include company policies, supervision, working conditions, salary and so on. If not adequately provided, hygiene factors contribute to dissatisfaction with work life. Factors having the potential to lead to job satisfaction were called motivators by Herzberg. They tend to be more intrinsic to or under the control of individuals and appeal to their need for growth and advancement, responsibility, achievement, and recognition. When motivators were present, individuals tended to feel satisfied with their work; when absent, they felt not satisfied, but not necessarily dissatisfied either. Herzberg concluded that the presence of hygiene factors is necessary, but not sufficient for work satisfaction. Figure 1 shows Herzberg's results.

While Herzberg's methodology has been criticized, his findings inspired the movement to redesign jobs. Resulting increases in quality of performance have been revealed in numerous experimental studies (Kopelman, 1986). In addition, Herzberg's theory has been widely used as a management tool in disciplines such as engineering management, manufacturing, nursing, health care management, consumer satisfaction, education, library construction, tourism, to name a few (Gnoth, 1997; Mcneesesmith, 1999; Poppleton, 1999; Stamatoplos \& Mackoy, 1998; Tuten \& August, 1998). By building motivational factors into the job content and allowing employees to assume responsibilities that were traditionally perceived as a manager's prerogative, organizations have been able to downsize, flatten their hierarchy, and increase productivity and profitability.

Building on Herzberg's research, Hackman and Oldham (1975) developed a job characteristic model that explains how Herzberg's job factors influence employee motivation and satisfaction. They found that jobs that score high on skill variety, task identity, task significance, autonomy, and feedback lead to high performance and satisfaction (Hackman \& Oldham, 1975).

Our research focuses on issues that emerged because of the growth of the Web as an information-seeking, retrieval, and application tool. It addresses aspects of all three of the big questions in Information Science, the physical question, the social question, and the design question (Bates, 1999). This new environment increasingly provides not only "universal access, ubiquitous context, and multimedia content, but enables integrated and distributed tasks that maximize 


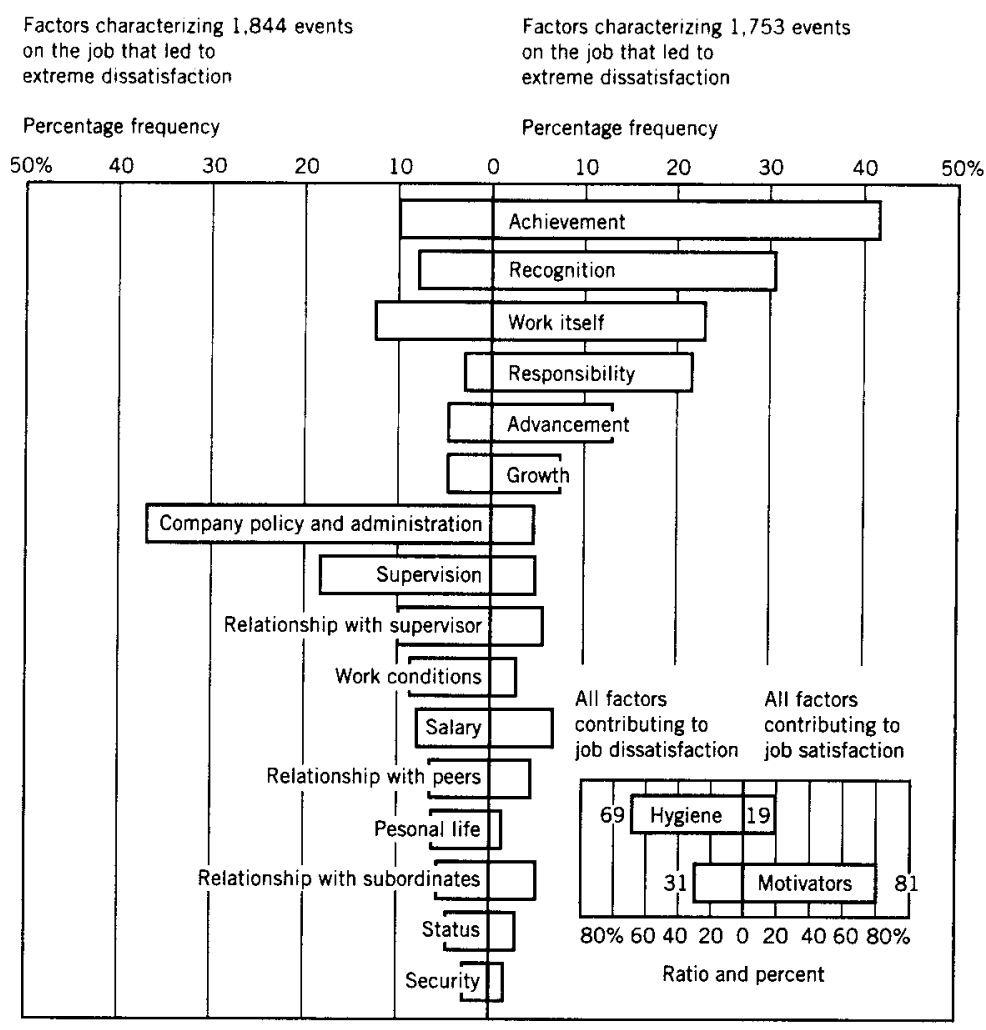

FIG. 1. Comparison of satisfiers and dissatisfiers. Source: Reprinted by permission of the Harvard Business Review. An exhibit from Herzberg, F. (1987, p. 112).

user control, learning, and information seeking as a process seamlessly embedded in larger work processes" (Marchionini \& Komlodi, 1998, p. 99). This study seeks to identify Web design factors that not only ensure technical functionality as promoted under the previous computing paradigms, but seek to maximize user capabilities to control, enjoy, and manipulate the information seeking process and its use (Koenemann \& Belkin, 1996; Shneiderman, 1988).

\section{A Two-Factor Model for Website Design and Evaluation}

The current researchers argue that there are several useful aspects of Herzberg's theory for Website studies. First, the dual structure, that is, the distinction between satisfaction and dissatisfaction as two dimensions rather than two values of the same dimension is logical and valuable. Not being dissatisfied does not mean being satisfied. Not being satisfied does not mean one is dissatisfied. Second, the concept of hygiene is appropriate once one understands its meaning as being preventive and environmental in nature (Luthans, 1995, p. 152). Third, relating factors to perceived satisfaction and dissatisfaction is a way of examining the factors in the Website environment. The intention here is not to validate Herzberg's theory as a motivational theory, but to use it as an intellectual tool to differentiate Website factors whose presence will be taken for granted by Website users from those that add value by creating a sense of satisfaction and enjoyment. From this perspective, the known criticisms to Herzberg's two-factor theory are not relevant to this study.

The researchers, therefore, propose a two-factor model for Web user interface studies that is analogous to Herzberg' two-factor theory in the work place. Accordingly, there should be basically two types of Website design factors: hygiene and motivator. Hygiene factors would be the ones whose presence make a Website useful and serviceable, whose absence cause user dissatisfaction. A good example of a Website feature that may be an example of a hygiene factor is "live/broken links," because a live link is taken for granted; but if the link is broken, users are frustrated and dissatisfied. Motivating factors, on the other hand, are those that contribute to user satisfaction. They add value to the Website beyond hygiene factor value alone. A possible example would be the use of multimedia in an information-intense Website. The presence of motivators will enhance satisfaction with the Website, while their absence will leave users feeling neutral, but not necessarily dissatisfied as long as the fundamentals or hygiene factors are in place.

The two-factor model has explanatory power. For example, when empirically examining how well and how poorly some information-rich Websites actually work when people use them to find specific information, Spool et al. (1999) found surprisingly that their criteria of "Users Like Most" and "Users Dislike Least" are not the same thing. When users said they disliked a site, their reasons usually related 
to some significant difficulties in using it. Users Dislike Least more closely matched the rankings in User Success. Spool et al. could not explain this effect. The two-factor model proposed in this study, however, can explain the case logically. Like (or satisfaction) and dislike (dissatisfaction) are two different things rather than two values of the same dimension. Thus, in the Spool et al. study, dislikes should have been caused by the lack of hygiene factors, while "Dislike Least" implies that users perceive that hygiene factors necessary to get jobs done are present. Therefore, "Dislike Least" rankings should be correlated to the reported User Success rankings, as reported by Spool et al. The model can explain further what Spool et al. discovered as a disturbing fact. Because they found that the sites users liked were often different from the ones they could successfully use, they concluded that this disturbing result implied that designing a site that users like and designing a site that they can use may be conflicting goals. The researchers disagree with Spool et al.'s conclusion because the twofactor model indicates that a site that users can use implies it has the necessary hygiene factors. But, it does not necessarily have the motivator factors, which are the reason users like a site. Being usable and being likable are two different goals, rather than conflicting goals.

According to Allport (1961), motivation includes a dimension of time. Whatever motivates us must motivate us in the present. Simply stated, it means that the reasons why individuals behave presently in a certain way are not the same reasons that originally caused that behavior. Consequently, one can assume that what individuals judge to be motivator today may not have motivated them a month ago or will not necessarily be motivating in the future. In addition, cognitive psychology theories propose that individuals pay attention only to stimuli that appeal to specific interests and needs at a given time, and that the strength of such stimuli weakens with time and familiarity (Pashler, 1998; Preece, Rogers, Sharp, Benyon, \& Holland, 1994). The present study collects users judgement of hygiene and motivator factors based on their present perceptions. To provide a base for future exploration of the time factor, this study also collected subjects' perception of the time impact on their hygiene/motivator judgement.

\section{Methodology}

Website design factors need to be clearly defined before Web users can judge them as hygiene and/or motivator factors in the Web environment. Current practice on Website design and existing studies on Website evaluation seem to focus on two levels of granularity: specific features, and categories that refer to a group of similar features. This study considers both levels as factors. Therefore, when there is a need to refer to a specific level, the specific term "feature" or "category" is used. Otherwise, the term "factor" refers to both levels. This empirical study was conducted in two phases: Phase I uncovers features and categories, and Phase II studies their hygiene and motivator characteristics.
Both phases use students (including undergraduate, master and doctoral students) and professional staff members associated with a private northeastern university in the United States as participants. They are not representative of the entire population of Web users. Rather, they can be considered experienced Web users owing to their number of years of using the Web and Internet, and number of hours per week on the Web (see detailed statistics in next session). This sample is appropriate owing to the characteristics of the empirical study where participants need to draw upon their experiences with the Web. More justifications for using this sample are provided in the Discussion section.

\section{Phase I: Identification of Features and Categories}

The objective of Phase I was to construct a list of comprehensible features organized into several categories. To do this, the researchers divided Phase I into two stages. During Stage 1, subjects were asked to group a set of preidentified features into commonly acceptable categories. Stage 2 consisted of verifying the classifications and refining the features and categories.

The researchers constructed a list of 74 features in the Web environment by applying Herzberg's two-factor theory in the work place to the Web. The procedure of applying this theory was a top-down process. We first examined the examples of events in the working place that define the categories of factors in Herzberg's theory. We then derived similar categories in the Web environment. To be more specific, we provided detailed categories in the Web environment to correspond to Herzberg's original categories so specific features could be identified. After we identified all the features we could think of, we examined and compared several existing Web checklists or Web usability study results (Conger \& Mason, 1998; Instone, 1997, Keeker, 1997; Levi \& Conrad, 1996; Sullivan, 1996; Wilkinson et al., 1997). We then refined the theoretically driven list accordingly resulting in a list of 65 features that was to be used in Stage 1.

The method used to gather data in Stage 1 was a "sorting game." Subjects received the set of features on small paper cards, and were asked to sort features into categories according to their own criteria. After sorting, participants were asked to give names to the categories created and write a definition for each of the categories. They were advised to classify features into only one category, corresponding to the best fit. A total of 39 students (six undergraduates, 30 graduate, and three doctoral students) generated usable data. These 39 subjects can be considered experienced Web users. Demographic information gathered showed that they have an average of 4.5 years of experience using the Internet/Web, and they spend an average of 11 hours per week on the Web. The 39 subjects reported an average of 56 minutes [standard deviation (std.) is 18 minutes] doing the task (including providing demographic data). They generated a total of 305 different categories. The number of 
categories per subject ranged from 4 to 13 with a mean of 7.8 (std. = 2.05), showing different levels of granularity.

Cluster analysis was used in Stage 1 to identify which features would group together. The cases of the cluster analysis were the categories the subjects named for the features they classified. Each subject's categories were treated as different cases, even though two subjects might have used the same name or definition for their categories. In this stage, there were 305 cases, which represent the sum of all categories defined by all the subjects. Hierarchical cluster analysis was conducted on these 305 cases and the 65 features. The similarity coefficient chosen for the analysis was Dice (also known as Czekanowski or Sorensen) to diminish the effect of the various degrees of granularity in the classifications done by the subjects. As pointed out by Bailey (1994), the task of choosing a "correct" cluster solution is not straightforward. We adopted a more heuristic approach combining a detailed analysis of the dendrograms and a content analysis of the names and definitions of the categories created by the subjects. The analysis of the dendrogram was intended to identify the "significant jumps" in the fusion coefficients (Aldenderfer \& Blashfield, 1984). Three cut points in the dendrogram showed equal maximum jumps, generating 6, 10, and 15 clusters, respectively. The choice for the 10-clusters solution was based on the semantic characteristics of the generated clusters. The researchers decided, additionally, to split one of the clusters into two (one level below in the dendrogram) based on the meaning in subjects' descriptions. One of these two clusters represented features that were more about user controls of different aspects of the Website, and the other cluster was more about navigational or structural aspects of a Website. As a result, 11 categories were found to represent a common classification of the features. Subjects also identified features that were not clear. Based on their comments, some features were reworded, some were combined, and some were divided.

The researchers named and described the 11 categories by considering the most inclusive and understandable terms used by the subjects. For example, one cluster had seven features and 39 cases (basically every subject had a case in

TABLE 1. Names of subjects' categories in stage 1.

\begin{tabular}{lc}
\hline Names given by subjects & $\begin{array}{c}\text { Number of subjects } \\
\text { who used the same name }\end{array}$ \\
\hline Aesthetics & 8 \\
Design & 5 \\
Attractiveness & 4 \\
Visual & 4 \\
Look/display & 4 \\
Web design & 4 \\
Appearance & 3 \\
User friendly & 2 \\
Graphics & 2 \\
Color schemes & 1 \\
Access & 1 \\
Website-technical aspect & 1 \\
\hline
\end{tabular}

this cluster). Table 1 shows the names given by the subjects for their categories and the numbers of subjects who used the same names. The researchers named this category "Visual Appearance" with the explanatory description "features related to the look of the Website."

Two additional categories (Surfing Activity and Cognitive Outcome) were added. These were primarily based on Herzberg's theory where job itself and advancement/growth were identified as motivator factors. The final results were 66 features and 13 categories.

In Stage 2 of Phase I, the subjects were 37 students, ranging from sophomores to doctoral students, all of whom were experienced Web users and did not participate in Stage 1 of Phase I. They were given the set of the 66 features and the 13 categories with names and descriptions displayed in a matrix. Their primary task was to classify each feature into the best matching category. They were then asked to identify other features that were missing from the feature lists but are members to any given category. A hierarchical cluster analysis was conducted. For each subject, the categories with the classified features were considered as individual cases for the analysis. There were a total of 448 cases of categories. This represents an average of 13 categories per subjects.

The dendrogram suggested 12 rather than 13 categories, with the original Privacy and Security combined as one category. Among the 66 features in Stage 1, one feature was combined with another feature owing to overlapping meanings ("User can/cannot control complexity of mechanisms for accessing information" and "Users can/cannot control the complexity level of mechanisms to explore information in the Website"). Seventy-four percent of the 65 remaining features were confirmed with the categories they belonged to in Stage 1. The other $26 \%$ features were judged to belong to different categories than those in Stage 1. For example, three features in the Organization of Information Content category in Stage 1 were judged to be features in the Navigation category in Stage 2; two features in the Information Content category in Stage 1 were Navigation features in Stage 2.

In Stage 2, there were categories that had overlapping features. That is, a number of subjects categorized the same features into different categories. For example, Navigation and Information Organization were not clearly distinguishable by their member features. From the cluster analysis, it did not seem appropriate to combine the two categories, as happened to Privacy and Security. The semantic relationship between information organization and navigation-a page with well-organized information would enhance navigation-may be a reason for such an overlap. Nevertheless, we kept these two categories separate.

Based on the results of this analysis, we identified a list of 44 features that seem unambiguous and carried high agreement among participants in placement in categories. These features are the core features for their categories. Thus, given a feature, the majority of the Web users would classify it into a certain category. These 44 core features and 


\section{Category}

C1. Surfing activity (features related to the characteristics of the surf activity itself, not the Website)

C2. Cognitive outcomes (features related to learning while using the Website)

C3. Enjoyment (features making the Website enjoyable, entertaining, fun)

C4. Privacy (features related to user privacy) and security (features related to access restrictions to the Website)

C5. User empowerment (features about the degree to which users can choose ways of surfing the Website)

C6. Visual appearance (features related to the look of the Website)

C7. Technical aspects (features related to the basic functions of the Website)

C8. Navigation (features related to moving around in the Website)

C9. Organization of information content (features related to the arrangement of the information content)

C10. Credibility (features related to Website's identify, reputation, recognition)

C11. Impartiality (features related to fairness, objectivity, and neutrality of the information content)

C12. Information content (features related to the amount and type of information covered)
Features

F1-1. The surfing activity has a high/low level of challenge.

F1-2. Importance/lack of importance of the surfing activity to the user.

F2-1. High/low level of learned new knowledge and/or skills by doing the surfing activity on the website.

F3-1. Presence/absence of use of humor.

F3-2. Presence/absence of multimedia.

F3-3. Fun/no fun to explore.

F4-1. Presence/absence of access requirement (e.g., pay a fee, sign on, enter a password, or provide some private info before one can access info).

F4-2. Authorized/unauthorized use of the user's data for unanticipated purposes.

F4-3. Authorized/unauthorized collection of user data.

F4-4. Presence/absence of assurance that user entered data is encrypted.

F5-1. Users can/cannot control order or sequence of information access.

F5-2. Users can/cannot control how fast to go through the Website.

F5-3. Users can/cannot control opportunities for interaction.

F5-4. Users can/cannot control complexity of mechanisms for accessing information.

F5-5. Users can/cannot control difficulty level of information to be accessed.

F6-1. Attractive/unattractive overall color use.

F6-2. Sharp/fuzzy displays.

F6-3. Visually attractive/unattractive screen layout.

F6-4. Attractive/unattractive screen background and pattern.

F6-5. Adequate/inadequate brightness of the screens/pages.

F6-6. Presence/absence of eye catching images or title on the homepage.

F7-1. Presence/absence of indication of system loading/responding time.

F7-2. Support/lack of support for different platforms and/or browsers.

F7-3. Stability/instability of the Website availability.

F8-1. Presence/absence of indicators of the user's location within the Website.

F8-2. Effective/ineffective navigation aids.

F8-3. Clear/unclear directions for navigating the Website.

F9-1. Presence/absence of overview, table of contents, and/or summaries/headings.

F9-2. Structure of information presentation is logical/illogical.

F10-1. High/low reputation of the Website owner.

F10-2. Presence/absence of external recognition of the Website (e.g., the site won awards, number of times the Website has been visited).

F10-3. Presence/absence of identification of site owners/designers.

F11-1. Biased/unbiased information.

F11-2. Presence/absence of gender or racial/ethnic biases and stereotypes.

F12-1. Information on the Website stays/does not stay for a period of time.

F12-2. Presence/absence of improper materials.

F12-3. Accurate/inaccurate information.

F12-4. Appropriate/inappropriate detail level of information.

F12-5. Up-to-date/outdated information.

F12-6. Relevant/irrelevant information.

F12-7. Complete/incomplete coverage of information.

F12-8. Content that supports/does not support the website's intended purpose.

F12-9. Presence/absence of controversial materials.

F12-10. Presence/absence of novel (new) information. the 12 categories, listed in Table 2, were used in Phase II to determine their hygiene and motivator nature. The subjects, despite being asked, identified no new features during this phase of the study.

\section{Phase II: Identification of Hygiene and Motivator Factors}

The goal of Phase II is to identify the hygiene and motivator characteristics of the categories and features developed and refined in Phase I. Several pilot studies of
Phase II indicated that some participants had difficulties in understanding the hygiene and motivator concepts when presented in a survey type instrument. Thus, Phase II of the study was conducted in multiple sessions, each in a class setting beginning with a short lecture on the basic concepts of hygiene and motivator factors in the work place. Then a quiz was administered to verify and ensure correct understanding. The subjects then completed a four part instrument: (1) a list of 44 core features and 12 categories, each feature or category to be in one of the four options: Hygiene, 
Motivator, Unclear H/M, and Unclear Wording, (2) demographic questions, (3) a questionnaire for gathering data on a subject's psychological profile, and (4) additional questions on potential impact of different contexts on their judgement. For participants to use a similar situation while evaluating the nature of features and categories, they were asked to draw upon the experiences they had while using the CNN.com Website or similar Websites for similar purposes. In the instruction of the instrument, the definitions of hygiene and motivator factors were stated one more time but using examples in the Web environment (these examples were not in the feature list of the instrument, thus should not bias the subjects' judgement on the features). Again, hygiene factors are related to dissatisfaction and motivator factors related to satisfaction.

All subjects were experienced Web users who had not participated in Phase I of the study. They comprised 79 individuals affiliated with a major northeastern university. Among them, 94\% were students (30 undergraduates, 35 graduates, and seven doctoral students) in a technologyoriented department. More than a quarter (27\% of the 79 subjects) reported that they hold full time jobs. There were 37 male and 42 female participants with an average age of $29($ std $=9)$. Subjects spent a self-reported average of 26 minutes (std. $=11$ ) on the instrument during individual sessions. Among the 79 subjects, only three had never visited the CNN.com Website and, therefore, used a different, but comparable context.

\section{Phase II Results}

The subjects' judgements of hygiene and motivator factors were summarized at three levels. The following section presents categories as hygiene and motivator factors. The section after that reports on features as H/M factors. In the third section, hygiene and motivator categories and their features are presented together. The last section concerns subjects' perceptions on the impact of other factors. These comments may provide useful insights for further investigation.

\section{Hygiene and Motivator Categories of Features}

Figure 2 shows the differences between the percentage frequency with which the subjects judged each category as hygiene or motivator. The hygiene side is represented by negative values to visually distinguish it from the motivator side. The categories are ordered by the difference in participants' judgements between motivator and hygiene percentage frequencies. For example, the difference of percentage frequency for $\mathrm{C} 3$ is $52 \%$ ( $76-24 \%$ ) in favor of the motivator judgment.

Similar to Herzberg's results in Figure 1, it appears that six categories (C3 Enjoyment, C2 Cognitive Outcomes, C10 Credibility, C6 Visual Appearance, C5 User Empowerment, and C9 Organization of Information) are motivator factors. The percentage frequency differences of these six categories

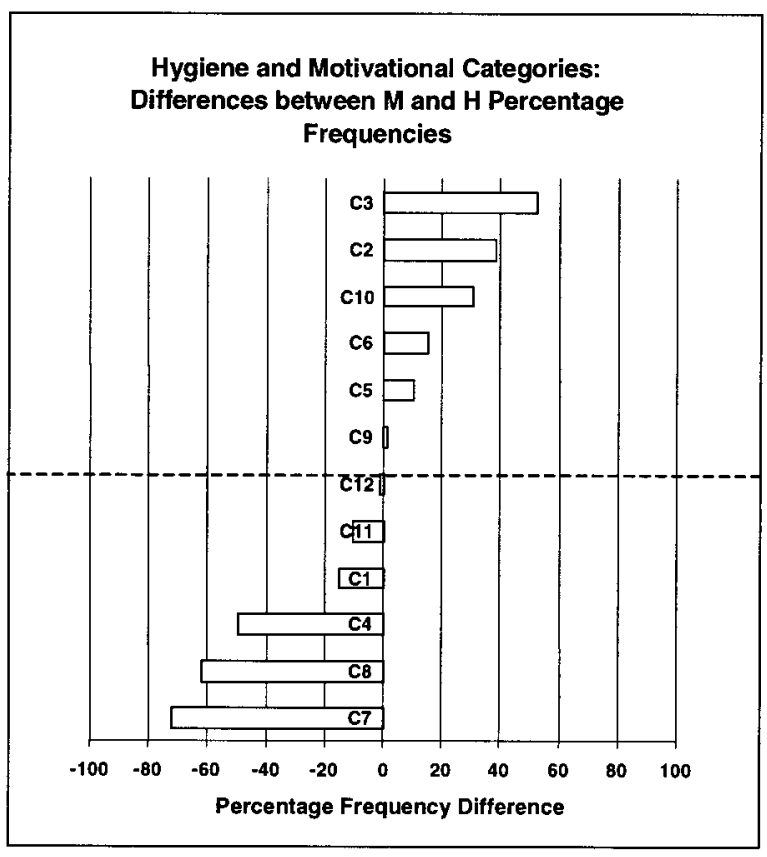

FIG. 2. Categories as H/M factors: difference of percentage frequency.

are C3 52\%, C2 38\%, C10 30\%, C6 15\%, C5 10\%, and C9 1\%. The other six categories (C7 Technical Aspects, C8 Navigation, C4 Privacy \& Security, C1 Surfing Activity, C11 Impartiality, and C12 Information Content) are hygiene factors. Their percentage frequency differences are $\mathrm{C} 7$ $72 \%, \mathrm{C} 862 \%, \mathrm{C} 4$ 49\%, C1 15\%, C11 10\%, and C12 1\%. For a full description of each category, refer to Table 2.

\section{Hygiene and Motivator Features}

Figure 3 shows the differences of percentage frequencies of the 44 core features in the order of the difference value. A dashed line separates the motivator features from the hygiene features. Table 3 is a list of all 44 features and their percentage frequency differences. It also includes the chisquare test for each of the features indicating the significant frequency differences among $\mathrm{H}$ and $\mathrm{M}$ judgements of the feature. Fourteen features have a nonsignificant chi-square value.

\section{Hygiene and Motivator Categories and Their Features}

Figures 4 and 5 depict all 12 categories and their features in two groups: hygiene and motivator. Upon examining each category in detail, it appears that there are three types of "correlations" among categories and their features. Type 1 shows that the judgement of a category is "supported by" or agrees with the judgement of all member features. Type 2 indicates categories with minor discrepancy of judgements between them and their features. Type 3 outlines those categories that are judged quite differently from their features. 
Hygiene and Motivational Features:

Differences between Percentage Frequencies

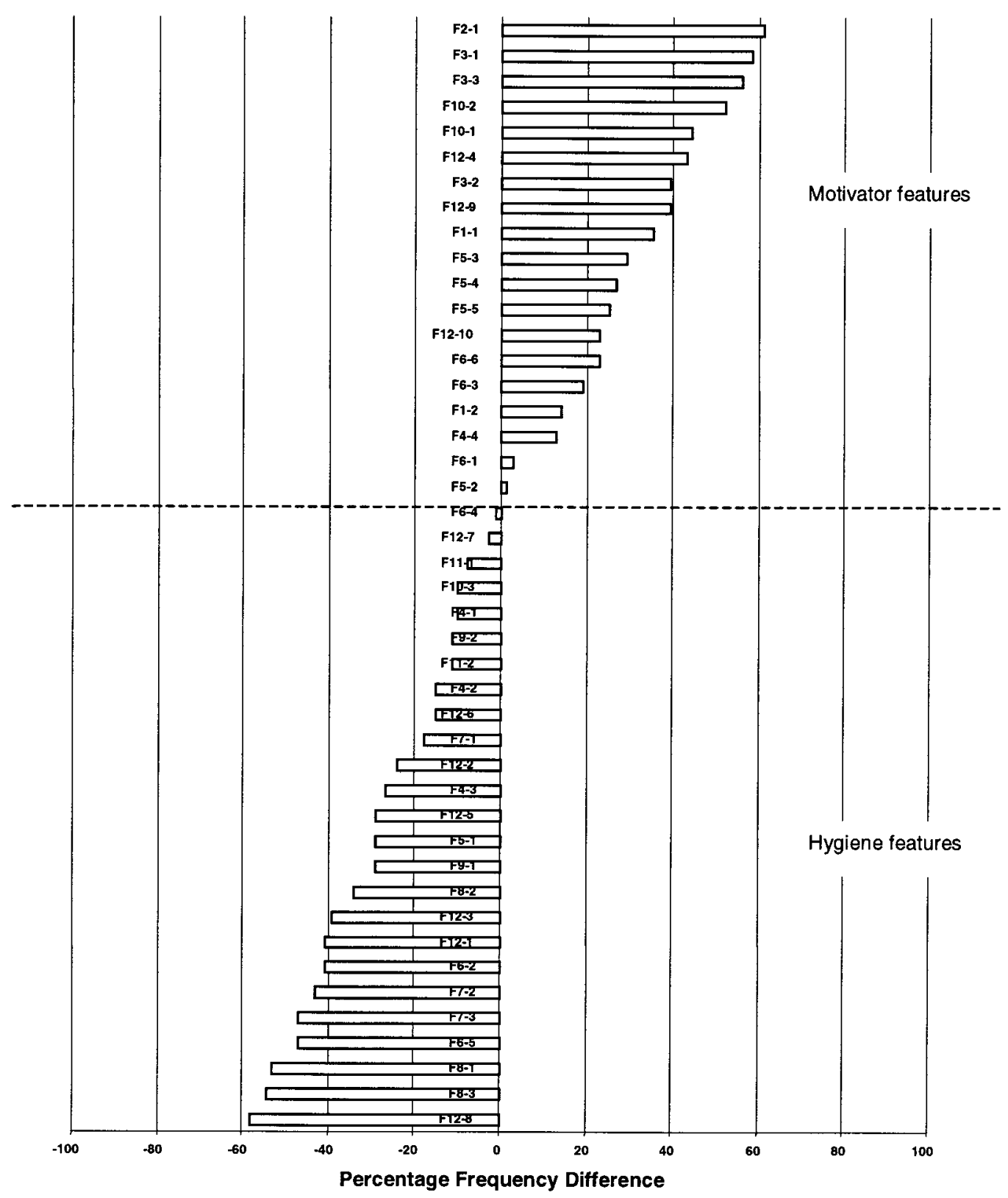

FIG. 3. Features of hygiene and motivator factors: difference of percentage frequency.

There are five Type 1 categories: C3, C2, C8, C7, and C11. Among them, C8, C7, and $\mathrm{C} 11$ are hygiene factors in Figure 4, while $\mathrm{C} 3$ and $\mathrm{C} 2$ are motivator factors, as shown in Figure 5. There are three Type 2 categories (C4 in Fig. 4, $\mathrm{C} 10$ and $\mathrm{C} 5$ in Fig. 5). The judgements on the remaining four categories do not quite agree with the judgements of their features. These four Type 3 categories are $\mathrm{C} 1$ and $\mathrm{C} 12$ in Figure 4, C6 and C9 in Figure 5.

Type 3 categories may imply that paying attention to the categories alone may not be enough for understanding the actual impact of the categories. This is because within each category, there might be features that are necessary to meet basic conditions as well as features that go beyond the basics to be motivational. This may help to explain the judgement about some of the categories such as C6, C5, and $\mathrm{C} 12$, with smaller percentage frequency differences. Some categories contain both hygiene and motivator features, and the determination of a particular category depends on the emphasis subjects put on either hygiene or motivator aspects of certain features within each category. As one subject pointed out, "Categories are nothing but a group of features. It may be a bit more difficult for a category to be 
TABLE 3. Hygiene and motivator features.

\begin{tabular}{|c|c|c|c|}
\hline & $\%$ Diff & $\chi^{2}$ & Features \\
\hline \multirow[t]{19}{*}{ Motivator } & $61 \%$ & .000 & $\begin{array}{l}\text { F2-1. High/low level of learned new knowledge and/or skills by doing the surfing activity on the } \\
\text { Website. }\end{array}$ \\
\hline & $58 \%$ & .000 & F3-1. Presence/absence of use of humor. \\
\hline & $56 \%$ & .000 & F3-3. Fun/no fun to explore. \\
\hline & $52 \%$ & .000 & $\begin{array}{l}\text { F10-2. Presence/absence of external recognition of the website (e.g., the site won awards, number } \\
\text { of times the Website has been visited). }\end{array}$ \\
\hline & $44 \%$ & .000 & F10-1. High/low reputation of the Website owner. \\
\hline & $43 \%$ & .000 & F12-4. Appropriate/inappropriate detail level of information. \\
\hline & $39 \%$ & .000 & F3-2. Presence/absence of multimedia. \\
\hline & $39 \%$ & .000 & F12-9. Presence/absence of controversial materials. \\
\hline & $35 \%$ & .001 & F1-1. The surfing activity has a high/low level of challenge. \\
\hline & $29 \%$ & .008 & F5-3. Users can/cannot control opportunities for interaction. \\
\hline & $27 \%$ & .015 & F5-4. Users can/cannot control complexity of mechanisms for accessing information. \\
\hline & $25 \%$ & .022 & F5-5. Users can/cannot control difficulty level of information to be accessed. \\
\hline & $23 \%$ & .042 & F12-10. Presence/absence of novel (new) information. \\
\hline & $23 \%$ & .042 & F6-6. Presence/absence of eye-catching images or title on the homepage. \\
\hline & $19 \%$ & .091 & F6-3. Visually attractive/unattractive screen layout. \\
\hline & $14 \%$ & .185 & F1-2. Importance/lack of importance of the surfing activity to the user. \\
\hline & $13 \%$ & .251 & F4-4. Presence/absence of assurance that user entered data is encrypted. \\
\hline & $3 \%$ & .821 & F6-1. Attractive/unattractive overall color use. \\
\hline & $1 \%$ & .909 & F5-2. Users can/cannot control how fast to go through the Website. \\
\hline \multirow[t]{25}{*}{ Hygiene } & $1 \%$ & .910 & F6-4. Attractive/unattractive screen background and pattern. \\
\hline & $3 \%$ & .821 & F12-7. Complete/incomplete coverage of information. \\
\hline & $8 \%$ & .480 & F11-1. Biased/unbiased information. \\
\hline & $10 \%$ & .359 & F10-3. Presence/absence of identification of site owners/designers. \\
\hline & $10 \%$ & .365 & F4-1. Presence/absence of access requirement. \\
\hline & $11 \%$ & .305 & F9-2. Structure of information presentation is logical/illogical. \\
\hline & $11 \%$ & .352 & F11-2. Presence/absence of gender or racial/ethnic biases and stereotypes. \\
\hline & $15 \%$ & .169 & F4-2. Authorized/unauthorized use of the user's data for unanticipated purposes. \\
\hline & $15 \%$ & .174 & F12-6. Relevant/irrelevant information. \\
\hline & $18 \%$ & .138 & F7-1. Presence/absence of indication of system loading/responding time. \\
\hline & $24 \%$ & .026 & F12-2. Presence/absence of improper materials. \\
\hline & $27 \%$ & .015 & F4-3. Authorized/unauthorized collection of user data. \\
\hline & $29 \%$ & .010 & F12-5. Up-to-date/outdated information. \\
\hline & $29 \%$ & .010 & F5-1. Users can/cannot control order or sequence of information access. \\
\hline & $29 \%$ & .009 & F9-1. Presence/absence of overview, table of contents, and/or summaries/headings. \\
\hline & $34 \%$ & .002 & F8-2. Effective/ineffective navigation aids. \\
\hline & $39 \%$ & .000 & F12-3. Accurate/inaccurate information. \\
\hline & $41 \%$ & .000 & F12-1. Information on the Website stays/does not stay for a period of time. \\
\hline & $41 \%$ & .000 & F6-2. Sharp/fuzzy displays. \\
\hline & $43 \%$ & .000 & F7-2. Support/lack of support for different platforms and/or browsers. \\
\hline & $47 \%$ & .000 & F7-3. Stability/instability of the website availability. \\
\hline & $47 \%$ & .000 & F6-5. Adequate/inadequate brightness of the screens/pages. \\
\hline & $53 \%$ & .000 & F8-1. Presence/absence of indicators of the user's location within the Website. \\
\hline & $54 \%$ & .000 & F8-3. Clear/unclear directions for navigating the Website. \\
\hline & $58 \%$ & .000 & F12-8. Content that supports/does not support the Website's intended purpose. \\
\hline
\end{tabular}

rated as $\mathrm{H} / \mathrm{M}$ as they have different features. But certain categories like visual appearance can come under $\mathrm{H}$ or M."

\section{The Impact of Other Factors}

One of the major perceived strengths of the Web is its capacity to customize services to meet the specific needs of individuals. Herzberg (1966) also discussed two types of people-hygiene seekers, and motivator seekers. He believed that they judge the same factor differently. Thus, the impact of individual differences on the subjects' judgements about hygiene and motivator factors might not be ignored.
There are many possible measures of individual differences. This study collected demographic data on subjects' (1) age, (2) gender, (3) academic classification (owing to the nature of the sample), (4) number of hours per week of using the Web, and (5) number of times using the CNN Website. An instrument for a psychological profile of a subject's preexisting motivational orientation, developed by Rotter (1966), was also used. Each of these six items was treated as a "factor" in the general loglinear analysis (chisquare was calculated) where the judgement of each of the 44 features and 12 categories was considered as the dependent variable. 
(4.1). C4 Privacy \& Security

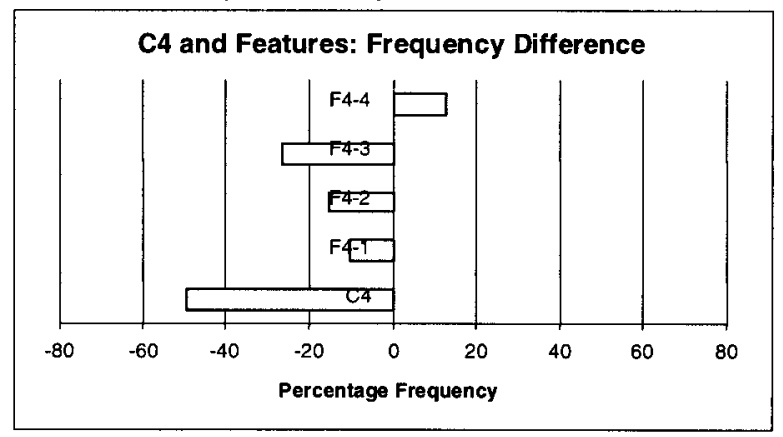

(4.3). C7 Technical Aspect

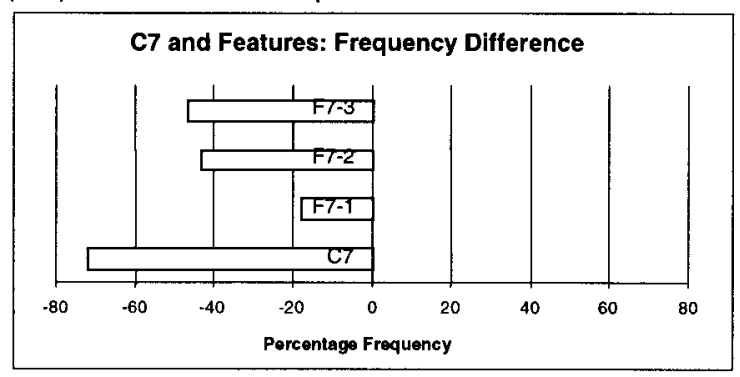

(4.5). C1 Surfing Activity

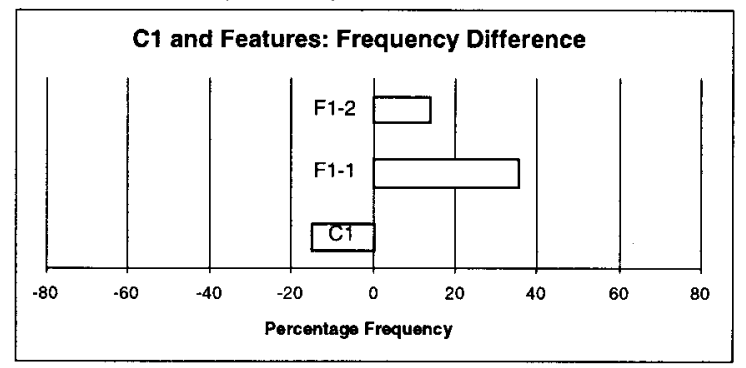

(4.2). C8 Navigation

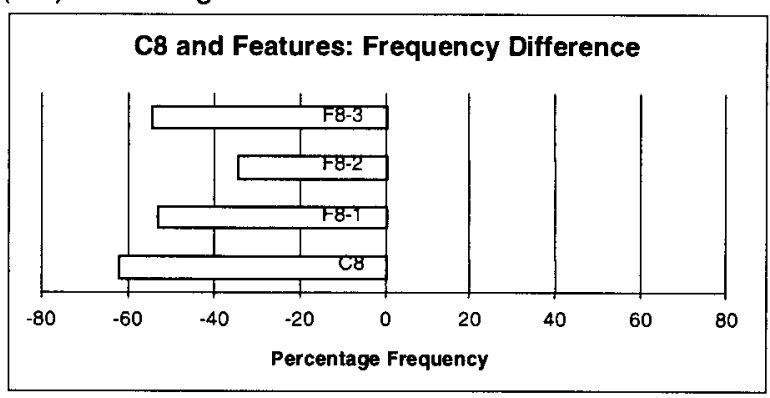

(4.4). C11 Impartiality

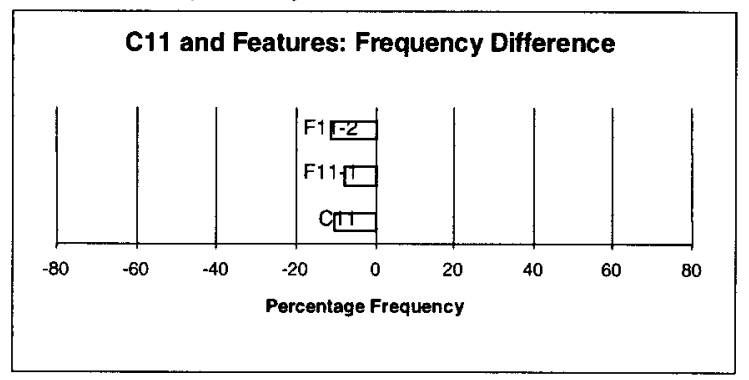

(4.6). C12 Information Content

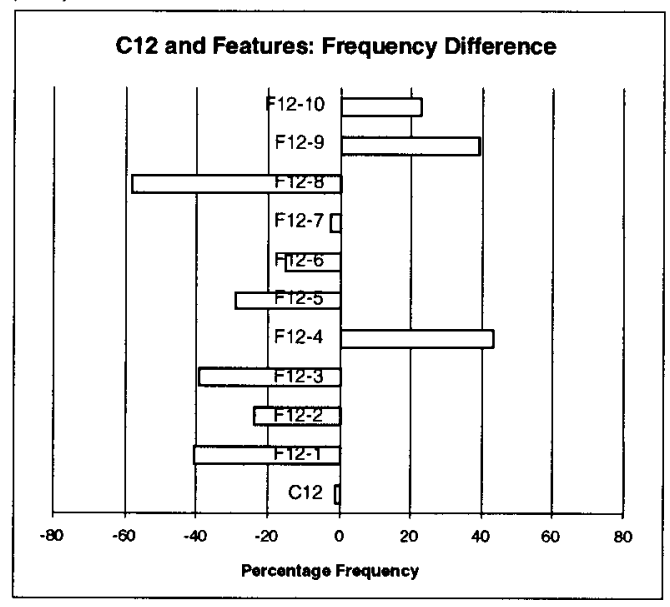

FIG. 4. Hygiene categories and their features.

The impact of individual differences on judgement is not significant. Few conclusive remarks can be made. This result may suggest further studies to investigate whether under different conditions (such as different Website types or tasks, different group of Web users), individual differences may affect H/M judgement.

The subjects, however, reported their perceived impact of individual differences on their judgement. When asked whether the judgement of an $\mathrm{H} / \mathrm{M}$ nature of a factor depended on individual differences, 68 out of the 69 subjects who answered the question said "yes." The specific differences listed explicitly by several subjects are in Table 4. This list may prompt future study on the potential impact of individual differences.

Subjects were also asked whether they thought that the types of Websites (such as entertainment, e-commerce, ed- ucation, etc.) will affect the $\mathrm{H} / \mathrm{N}$ nature of features and categories they judged. Eighty-six percent of the subjects who answered this question believed that the Website types do affect the way they judge hygiene or motivator factors. Specifically, subjects commented that they expect entertainment Websites to be more active, fun, enjoyable, visually attractive with bright colors and animation. They expect serious purpose Websites (such as financial news, business transactions or e-commerce) to have accurate and updated information, security and privacy, and reputation. They expect educational sites to have accurate, factual, nonbiased and richer materials. Thus, as an example, visual appearance is hygiene for entertainment Websites but motivator for educational Websites. Security and reputation are hygiene for e-commerce sites but that may not be true for educational Websites. The other $14 \%$ thought that certain features 


\section{(5.1). C3 Enjoyment}

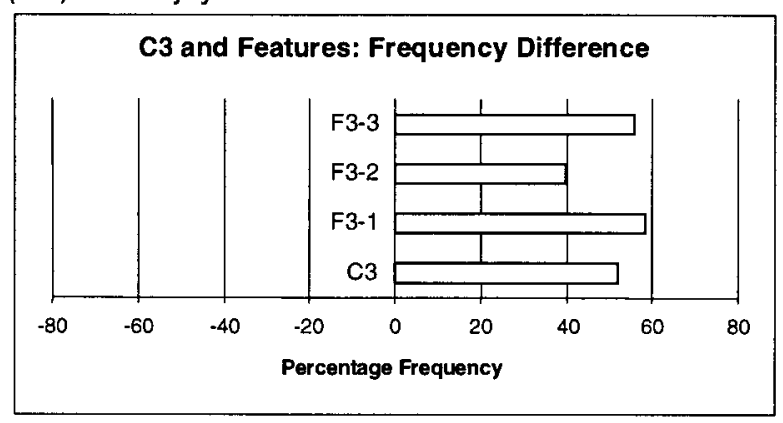

(5.3). C10 Credibility

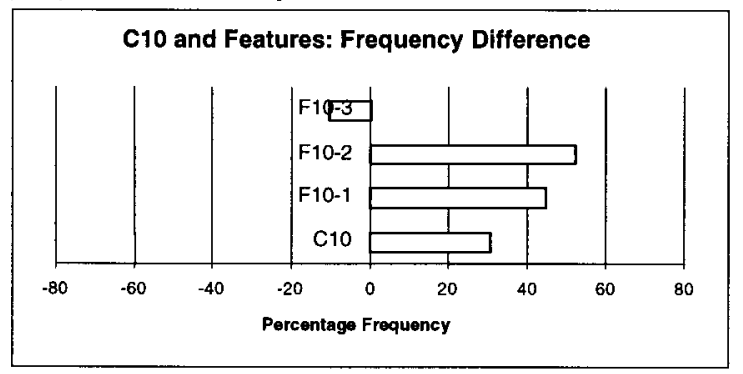

(5.5). C5 User Empowerment

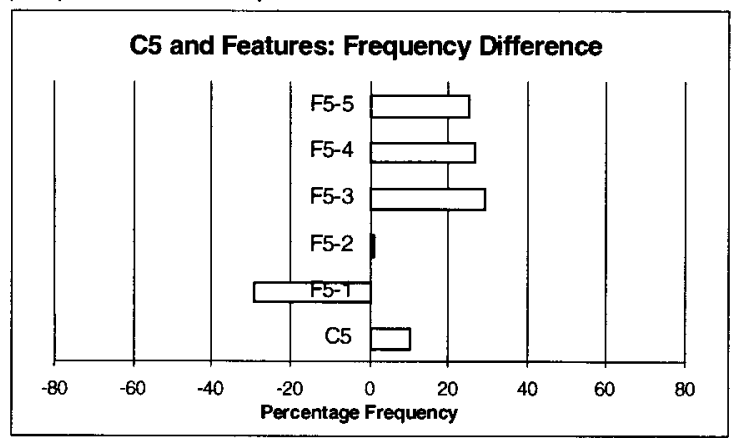

(5.2). C2 Cognitive Outcome

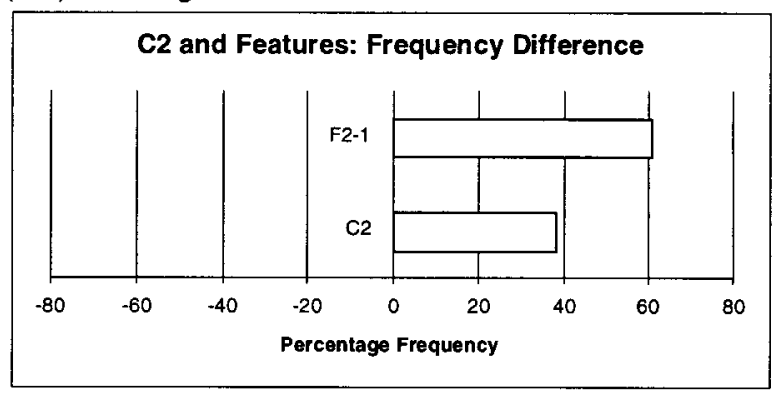

(5.4). C6 Visual Appearance

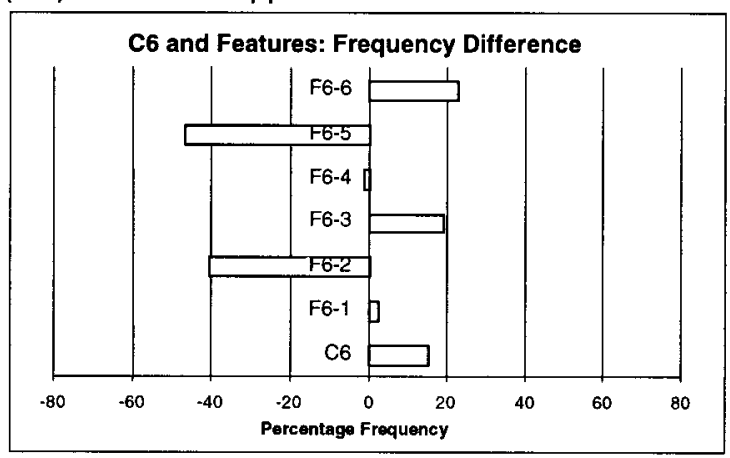

(5.6). C9 Organization of Info. Content

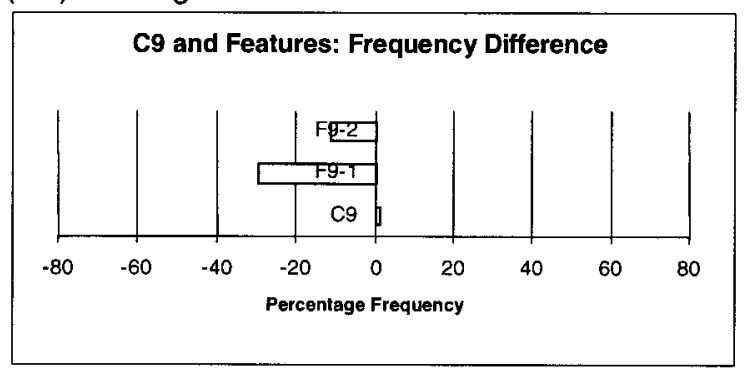

FIG. 5. Motivator categories and their features.

have a universal effect for either hygiene or motivator regardless of Website types. They believed that there are base functions that every Website needs, such as navigation, clear content, privacy statements, etc.

Subjects were also asked whether the H/M nature of a factor might change as time passed. The responses were overwhelmingly one-sided: 62 yes versus one unsure (and 16 did not answer the question). The majority of the 62 subjects asserted that motivator factors would change into hygiene factors as time passed. Table 5 shows the most listed reasons for the change.

\section{Discussion}

In this section, the researchers discuss the empirical evidence on $\mathrm{H} / \mathrm{M}$ factors and the theoretical implications of the two-factor model for Website design. Practical implica- tions for Website designers and evaluators follow. The researchers then present some insight into the research design and process including challenges and difficulties. Finally, the limitations of the study, and some future research directions are presented.

TABLE 4. Subjects reported individual differences that may affect $H / M$ judgement.

Individual characteristics

Number of responses

Expectations, standards, interests, wants/needs, purposes 12 Previous experience with the web 
TABLE 5. The most listed reasons for $\mathrm{H} / \mathrm{M}$ nature to change as time passes.

\begin{tabular}{lc}
\hline \multicolumn{1}{c}{ Individual characteristics } & $\begin{array}{c}\text { Number of } \\
\text { responses }\end{array}$ \\
\hline $\begin{array}{l}\text { Users' increased expectations (people's nature: always } \\
\text { looking for improvement, users are more demanding) }\end{array}$ & 19 \\
$\begin{array}{l}\text { Users' increased experience with the web (get used to } \\
\text { certain factors, certain factors become norm) }\end{array}$ & 13 \\
$\begin{array}{l}\text { The advancement of technologies } \\
\text { Competition for recognition (website designers competing } \\
\text { for being the best) }\end{array}$ & 5 \\
\hline
\end{tabular}

\section{Empirical Evidence and Theoretical Implications}

The empirical evidence shows that participants could identify or distinguish hygiene and motivator factors in the Web environment. The findings are very similar to what Herzberg found in the work environment in that there are hygiene factors and there are motivator factors. The clearly identified hygiene categories include C7 Technical Aspects, C8 Navigation, and C4 Privacy \& Security (see Fig. 2). Most of their features tend to have the same H/M characteristics (refer to Fig. 4). These categories and features address more of the functional aspect of a Website. They are perceived to be the ones that contribute to user dissatisfaction if absent or inadequately provided.

The clearly identified motivator categories are C3 Enjoyment, C2 Cognitive Outcome, and C10 Credibility (see Fig. 2). Again, most of their features were perceived to have similar H/M characteristics (refer to Fig. 5). These categories and features are closely related to individuals' interaction with a Website, rather than just the Website itself. That is, these factors make users feel they are involved, either cognitively or emotionally while interacting with the Website. They are the factors that contribute to one's satisfaction with a Website when present or considered.

The other six categories, although each of the participants made a judgement, are less clear than the above six categories. The reasons for this could be similar to those identified in Herzberg's study, for instance situational or individual differences. Among these six categories, the most interesting categories to the researchers are C9 Organization of Information and C12 Information Content (see Fig. 2), which were perceived almost equally as both hygiene and motivator (about 1\% difference). This result can be compared to the Salary factor in Herzberg's study, which was also almost equally perceived as hygiene and motivator. That does not mean that the Salary factor is unimportant; the implication is that this type of factor is more complex than other factors, and could be more dependent on situational or individual differences. In addition, Figures 4 and 5 suggests that the features of these categories have mixed H/M characteristics. The category level of analysis may not be sufficient to reveal the potential impact of the categories.

Among the core features, there are clearly identifiable motivators and hygiene features. There are also features that were almost equally judged as either hygiene or motivator features, and they seem to be sensitive to the situational or individual differences. Nevertheless, we decided to separate the hygiene and motivator features from a theoretical perspective at the moment. Meanwhile, we realize that the current two-factor model is limited to examine this particular group of features clearly, thus it is tentative and needs further studies.

Although further rigorous investigation is needed to reveal more aspects of the model, this study also provides some clues that the two-factor model in the Web environment is not quite like its counterpart in the workplace. Specifically, participants perceived a very strong time impact on their $\mathrm{H} / \mathrm{M}$ judgement of the design factors. This is not explicitly mentioned in Herzberg's theory. The perceived time impact provides some tentative data that prompt further investigation. If the time impact is true, a possible expansion of the two-factor model should be considered.

\section{Practical Implications for Website Designers and Evaluators}

Understanding the contributing factors to user satisfaction and dissatisfaction with Websites is important for both Website designers and independent Website evaluators. Website designers first need to minimize user dissatisfaction by providing hygiene factors while being aware that these factors are not sufficient to generate user satisfaction. Second, to keep a competitive advantage in an increasingly competitive Web environment, Website designers need to constantly identify and build motivational factors into their Websites. Thus, hygiene factors have higher priority and function as a prerequisite for the motivator factors that add cognitive and affective values.

The results of this study also provide a framework for independent evaluators to assess Website designs. As an example pointed out earlier, this two-factor model can explain some empirical evidence that Spool et al. (1999) could not explain. Thus, this study adds value to the existing Web usability methods and techniques.

Several other findings of the study might be beneficial to designers and evaluators. The perceived time impact reported by the participants shows potential dynamics of human interaction with the Web environment. No factors should be regarded as motivators forever. If the time impact is valid, for designers, this means the need to constantly study their users and improve their designs to stay competitive. For evaluators, this implies that different evaluation results can be achieved at different time points for the same design owing to the time impact. Website types may affect a user's perception on a particular factor's H/M characteristics. Designing an entertainment Website requires different hygiene and motivator factors than an education Website. Consequently, it is important for Website evaluators to be aware of the different roles the same factors have for different types of Websites. 
Some Insight into the Research Design and Process

There were several difficulties and challenges encountered during the research design and data collection process. Some of them were mirrored by the collected data.

(1) Treating satisfaction and dissatisfaction as two dimensions rather than two values of the same dimension is conceptually clear and logical but difficult to apply or use. It is easy to fall into the two-values-of-the-samedimension trap. The two-dimension concept is not intuitive or familiar to most people. It is cognitively demanding to work with the two-dimension concept because it requires consciously reminding oneself of the distinction.

(2) C1 "Surfing activity" was defined as the Web equivalent of Herzberg's "work itself." The researchers realized that the granularities of Herzberg's work and the task of surfing the CNN Website are different. In addition, surfing the CNN Website may have little to do with work related tasks, and is purely for leisure. Thus, surfing may have less or more impact on satisfaction than interesting work itself would have on one's job satisfaction. As the data show (see Fig. 2), C1 was judged as a hygiene factor compared to a motivator in Herzberg's results.

(3) C8 (Navigation) and C9 (Organization of Information Content) are conceptually related categories. For example, a good organization of information content can facilitate navigation. This relationship was shown as an overlap in the classification results in Phase I. To make a clear division, the researchers defined them as a functionality (C8) versus emphasizing the logic of presenting the information content itself (C9).

(4) When evaluating a particular Web feature as a hygiene or motivator factor, one needs to think in terms of presence or absence of the feature. This posed a challenge in defining the meaning or semantics of the feature as unambiguously as possible. After many trials and focus group sessions, the researchers decided to label a feature's values explicitly to restrict other possible meanings of the feature. For example, "Broken/ live link" refers to one feature rather than just "link," as is "Presence/absence of use of humor" rather than "Use of humor."

(5) Focus groups revealed that many subjects had difficulties in understanding the concept of hygiene and motivator factors when they were presented in writing as part of the instructions for the questionnaire. In addition, some subjects had difficulties in making the transition from work environment to the Web environment. Consequently, the researchers changed data collection methods for Phase II from administering just a questionnaire to lecturing on the basic concepts of hygiene and motivator in the work place prior to distributing the questionnaire. The instrument also provided one example each, which was not used in the instrument, of what might be considered to be a $\mathrm{H} / \mathrm{M}$ feature in the $\mathrm{Web}$ environment.

\section{Limitations of the Research}

The identification of $\mathrm{H} / \mathrm{M}$ factors in the Web environment in this study is constrained by the specific task on a specific Website by this particular user population at the present time. Several aspects of the study may suggest the limitations of the research.

(1) Number of participants for Phase II. Because percentage frequency was the main data analysis method, the number 79 is not a large enough one to be significant.

(2) Phase II relying on recall of experiences of using the CNN or similar Website rather than actual use. For this reason, situational factors (such as time of the day, reasons for surfing, to name a few) influencing the actual use of the CNN or a similar Website may not be reflected in the judgement of particular features or categories.

(3) Only one type of Website for Phase II (CNN or similar popular news and information site).

(4) Homogeneous subjects. All 155 participants in Phases I and II were people associated with a northeastern university in the United States. More than $90 \%$ were students in two professional schools, and therefore, are highly skilled at tasks related to information seeking, manipulation, and use. Their experience with the Web and the average weekly hours spend on the Web might make the findings of the study difficult to be generalized to other populations of Web users.

On the other hand, the perceived time impact on $\mathrm{H} / \mathrm{M}$ judgement of Web factors may further provide a justification for using people primarily associated with universities as representatives for Web users in this study. First, this study shows that there is a division of design factors that contribute respectively to user satisfaction and dissatisfaction with Websites. That is, the goal was to show that there is a "line" between basically two types of factors, rather than showing exactly where the line is. The perceived time impact means that the line is a fluctuating one depending on users' familiarity with the design factors. Using experienced users does not affect the fact that there is a line. Second, it is an accepted practice to ask experts or experienced people to do classifications, as the case in Phase I where the results of the classification should represent most Web users' classification.

\section{Future Research Directions}

The primary focus of this study is to gain confidence about the two-factory model in the Web environment to investigate Website design factors from a systematic and theoretical perspective. Identifying exactly which factor is hygiene and which is motivator is secondary, and is believed to be situational. Nevertheless, the study did find some highly convergent hygiene and motivator factors. Future research can be designed to answer the following questions. 
(1) Is the two-factor model credible across user information seeking tasks [e.g., browsing and analytical strategies by Marchionini (1995)], Website types (entertainment, e-commerce, education, government, etc.), and by a broader Web user population?

(2) If the time impact on $\mathrm{H} / \mathrm{M}$ judgement is true, how should one incorporate the time dimension into the two-factor model?

(3) Is there a common group of hygiene or motivator factors across different Website types?

(4) Are some hygiene or motivator factors more or less important in creating user dissatisfaction or satisfaction?

(5) Which individual differences and needs account for variations in $\mathrm{H} / \mathrm{M}$ judgement?

\section{Acknowledgments}

The authors wish to thank Dr. Ruth Small and doctoral student Silvia Barcellos in the School of Information Studies at Syracuse University for their contributions to the early stage of the project. The authors also thank Dr. Michael D'Eredita, and doctoral students Jiangping Chen and Naybell Hernandez for their assistance in conducting some of the empirical sessions. The authors are very grateful for comments on early drafts from Drs. Jeffrey Katzer, Kevin Crowston, Robert Heckman, Carol Hert, Jian Qin, Dmitri Roussinov, and Ian MacInnes. Finally, the authors wish to thank the two anonymous reviewers for their constructive comments and suggestions. This research is partially supported by a research grant from Syracuse University School of Information Studies.

\section{References}

Aldenderfer, M.S., \& Blashfield, R.K. (1984). Cluster analysis (vol. 44). Newbury Park, CA: Sage Publications.

Alexander, J., \& Tate, M.A. (1999). Web wisdom: How to evaluate and create information quality on the Web. Hillsdale, NJ: Lawrence Erlbaum Associates.

Allport, G.W. (1961). Paatern and growth in personality. New York: Holt, Rinehart and Winston.

Baecker, R., Grudin, J., Buxton, W.; Greenberg, S. (1995). Readings in human-computer interaction: Toward the year 2000 (2nd ed). San Francisco, CA: Morgan Kaufmann Publishers.

Bailey, K.D. (1994). Typologies and taxonomies: An introduction to classification techniques (Vol. 102). Newbury Park, CA: Sage Publications.

Bates, M.J. (1999). The invisible substrate of information science. Journal of the American Society of Information Science, 50(12), 1043-1050.

Borges, J., Morales, I., Rodriguez, N. (1998). Page design guidelines developed through usability testing. In C. Forsythe, E. Grose, and J. Ratner (Eds). Human factors and Web development (pp. 137-152). Hillsdale, NJ: Lawrence Erlbaum Associates.

Burton, F.G., Chen, Y., Grover, V., Stewart, K A. (1993). An application of expectancy theory for assessing user motivation to utilize an expert system. Journal of Management Information Systems, 9(3), 183-198.

Conger, S.A., \& Mason, R.O. Planning and designing effective Web sites. Cambridge, MA: Course Technology.

DeSanctis, G. (1983). Expectancy theory as an explanation of voluntary use of a decision-support system. Psychological Reports, 52, 247-260.

Flanders, V., Willis, M. (1998). Web Pages that suck. San Francisco, CA: SYBEX Inc.
Gill, T.G. (1996). Expert systems usage: Task change and intrinsic motivation. MIS Quarterly, Summer, 301-329.

Gnoth, J. (1997). Tourism and motivation and expectation formation. Annals of Tourism Research, 24(2), 283-304.

Hackman, J.R., \& Oldham G.R. (1975). Development of the job diagnostic survey. Journal of Applied Psychology, April, 159-170.

Herzberg, F. (1966). Work and the nature of man (Chapter 6, pp. 71-91). New York: World Publishing.

Herzberg, F. (1968). One more time: How do you motivate employees? Harvard Business Review, January-February, 53-62.

Herzberg, F. (1987). One more time: How do you motivate employees? Harvard Business Review, September-October, 109-120.

Instone, K. (1997). Usability heuristics for the Web. http://webreview.com/ 97/10/10/usability/sidebar.html

Keeker, K. (1997). Improving Web site usability and appeal: Guidelines compiled by MSN Usability Research, July 24, 1997. Http://msdn. microsoft.com/workshop/management/planning/IMPROVINGSITEUSA. asp.

Koenemann, J., \& Belkin, N.J. (1996). A case for interaction: A study of interactive information retrieval behavior and effectiveness. In Tauber, M. (Ed). CHI'96: Proceedings of the association for computing machinery special interest group on computer-human interaction (ACM/SIGCHI) conference on human factors in computing systems (pp.205-212); April 13-18, Vancouver, B.C. New York: ACM.

Kopelman, R.E. Managing productivity in organizations. New York: McGraw Hill.

Kreitner, R., Kinicki, A. Organizational behavior (4th ed). Boston, MA: Irwin, McGraw-Hill.

Levi, M., \& Conrad, F. (1996). A heuristic evaluation of a World Wide Web prototype. Interactions, 3(4), 50-61.

Luthans, F. (1995). Organizational behavior (7th ed.). New York: McGraw-Hill.

Marchionini, G. (1995). Information seeking in electronic environments. Cambridge, MA: Cambridge University Press.

Marchionini, G., \& Komlodi, A. (1998). Design of interfaces for information seeking. Annual review of information science and technology (ARIST) (vol. 33, pp. 89-130). Medford, NJ: Information Today, Inc.

Markus, L.M., \& Keil, M. (1994). If we build it, they will come: Designing information systems that people want to use. Sloan Management Review, Summer, 11-25.

Maslow, A. (1954). Motivation and personality. New York: Harper \& Row.

McClelland, D.C. (1961). The achieving society. New York: Van Nostrand Reinhold.

Mcneesesmith, D.K. (1999). The relationship between managerial motivation, leadership, nurse outcomes and patient satisfaction. Journal of Organizational Behavior 20(2), 243-259.

Nielsen, J. (1999). User interface directions for the Web. CACM, 42(1), 65-72.

Nielsen, J. (1993). Usability engineering. New York: AP Professional.

Nielsen, J. n.d. Alertbox.

Pashler, H. (1998). The psychology of attention. Cambridge, MA: The MIT Press.

Poppleton, P. (1999). Teacher morale, job-satisfaction and motivation, by L. Evans. Teaching and Teacher Education, 15(3), 325-331.

Preece, J., Rogers, Y., Sharp, H., Benyon, D., Holland, S., Carey, T. Human-computer interaction. Reading, MA: Addison-Wesley.

Rotter, J.B. (1966). Generalized expectancies for internal versus external control of reinforcement. Psychological Monographs, 80 (Whole No. 609).

Shneiderman, B. (1998). Designing the user interface-strategies for effective human-computer interaction (3rd ed.). Reading, MA: AddisonWesley.

Shneiderman, B. (1988). Designing the user interface: Codex, memex, genex: The pursuit of transformational technologies. International Journal of Human-Computer Interaction, 10(2), 87-106. 
Small, R.V. (1998). Assessing the motivational quality of World Wide Websites. Syracuse, NY: ERIC Clearinghouse on Information and Technology (ED 407 930).

Smith, A. (1997). Testing the surf: Criteria for evaluating Internet information resources. The Public-Access Computer Systems Review, 8(3).

Spool, J., Scanlon, T., Schroeder, W., Snyder, C., DeAngelo, T. Web site usability-A designer's guide. San Francisco, CA: Morgan Kaufmann Publishers, Inc.

Stamatoplos, A., \& Mackoy, R. (1998). Effects of library instruction on university-students satisfaction with the library-A longitudinal-study. College \& Research Libraries, 59(4), 323-334.
Sullivan, T. (1996). User testing techniques-A reader-friendliness checklist. Tuten, T.L., \& August, R.A. (1998). Understanding consumer satisfaction in services settings-A bidimensional model of service strategies. Journal of Social Behavior and Personality, 13(3), 553-564.

User Interface Engineering. (1996). Surprises on the Web: Results from usability testing. http://world.std.com/ uieweb/surprise.htm

Vessey, I. (1991). Cognitive fit: A theory-based analysis of the graph versus tables literature. Decision Sciences, 22.

Vroom, V.H. (1964). Work and motivation. New York: John Wiley.

Wilkinson, G.L., Bennett, L.T., \& Oliver, K. M. (1997). Evaluation criteria and indicators of quality for Internet resources. Educational Technology, May-June, 52-59. 